\title{
Second Order Low Pass RC Active Filter for Low Frequency Signal Processing
}

\author{
Raj Kumar Tiwari, Professor, Physics and Electronics Department, Dr. R.L.A. University \\ Ayodhya, U.P. India, rktiwari2323@gmail.com \\ Shiksha Jain, Assistant Professor, Electronics and Communication Department, Dr. R.L.A. \\ University Ayodhya, U.P. India, shiksha98jain@gmail.com
}

\begin{abstract}
The different parameters define the characteristics of filter for various applications like: Biomedical applications, Defense communication systems, Wireless Communication systems etc. The mostly measured parameters for filter designing are frequency range, cut off frequency, gain, power consumption, and noise. In this paper, our work focuses on frequency range measurement at cut off frequency of $\mathrm{Hz}$ of second order low pass filter with designed using CMOS technology for IC fabrication. The proposed circuit gives the high frequency range at low frequency $(100 \mathrm{~Hz}-$ $10 \mathrm{MHz}$ ) with $1 \mathrm{mV} 50 \mathrm{~Hz}$ low power supply using complementary compound pair on the value of $R=1 \mathrm{~K}$ and $\mathrm{C}=10 \mathrm{pH}$. This second order active low pass filter provides high amplification at the output with $4.861 \mathrm{~V}$. It is implemented and simulated on 180nm Cadence tool in terms of wide frequency range or band at cut off frequency of $\mathrm{Hz}$ to $\mathrm{MHz}$.
\end{abstract}

Keywords: Complementary Compound Pair, Cut off frequency, Low Pass Filter.

\section{INTRODUCTION}

In the present time, electronics field is playing the vital role in advanced development of research areas like: Biomedical field, Defense area, Aeronautical field space system etc. These above areas have major challenges urge to the system with very low cost, low power consumption, very high gain, wide spread band etc.

Mostly systems mentioned above have preprocessing blocks such as low noise preamplifier and filters for the possession of low frequency signals are employed. These blocks should not have any type of distortion that can explode the necessary signal. To meet these requirements, the preprocessing blocks must have present high performance over the gain and frequency for low frequency signal processing. To achieve the required parameters for signal processing, different topology based filters like: Switched-Capacitor Based Topology for Voice Band Applications, gm-c Filters, Feedback and Cancellation topology has been designed. But these offers some disadvantages like clock feed-through, aliasing problem, temperature dependent etc. [1] - [4]. To avoid the above problems, we have designed a high frequency range at low frequency second order active low pass filter using complementary compound pair. It provides very high current gain in case of BJT (Bipolar Junction Transistor) and very high voltage gain in case of MOS (Metal Oxide Semiconductor) to avoid the dependency of temperature and provide low frequency signal amplifications with low power consumption. It is a monolithic filter for IC fabrication.

\section{A. Complementary Compound CMOS Pair:}

This complementary compound pair using CMOS has more advantages than the Darlington Pair and Sizilai Pair. It is a special combination of two NMOS and two PMOS transistor connected in the form of Darlington structure to produce more special characteristics of transistor with a larger current gain and voltage gain useful in signal processing [5]. The block diagram of complementary compound CMOS pair is given below in "Fig.1". This innovative pair is designed to enhance the band of the amplifier with negligible power consumption and gain boosting of the amplifier with suitable value of $\mathrm{W} / \mathrm{L}$ ratio used for low frequency signal processing [6],[7].

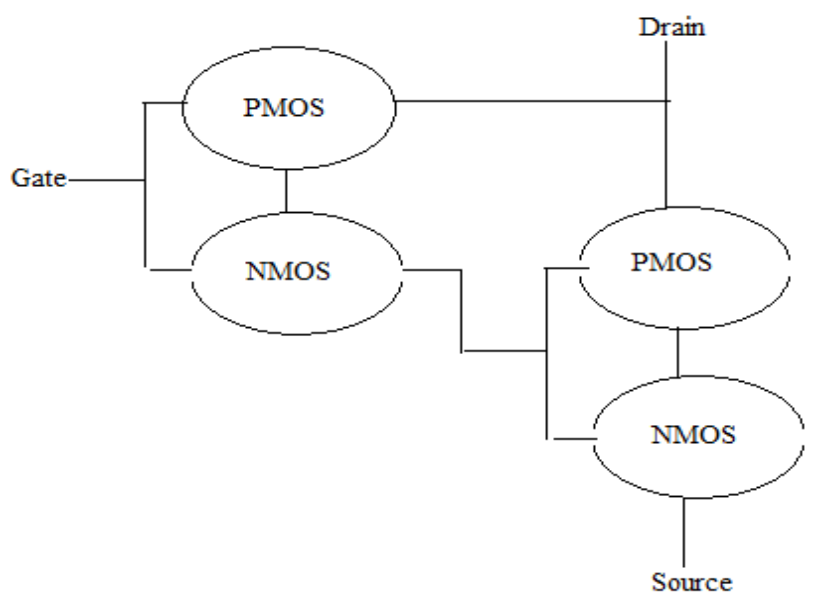

Fig. 1 Model of Complementary Compound Pair

These are necessary parameters to analyze the performance of any type of filter for signal processing. 


\section{B. Active Low Pass Filter:}

An electrical filter is a processing system to filter all unwanted frequencies signal from the required signal for accurate output. In other words, it is a totally frequency depended system with varying gain, power dissipation, noise in the system, speed etc. The frequency of the system is based on the active and passive component used in the circuit designing like: amplifiers as active component and inductor, resistor \& capacitor as a passive component. The cut off frequency is a major parameter for any types of filter because this frequency separates the band like: stop band and pass band, transition band etc. Active low pass filter can be design using RC or LC network with amplifier circuit to produce high attenuation above a cut off frequency and negligible attenuation below that frequency. In an active RC low pass filter, the time constant $\zeta \mathrm{c}$ is determined by $\mathrm{RC}$ products, accurate to only $20-50 \%$. The ideal frequency response of active low pass RC filter is shown in "Fig.2".
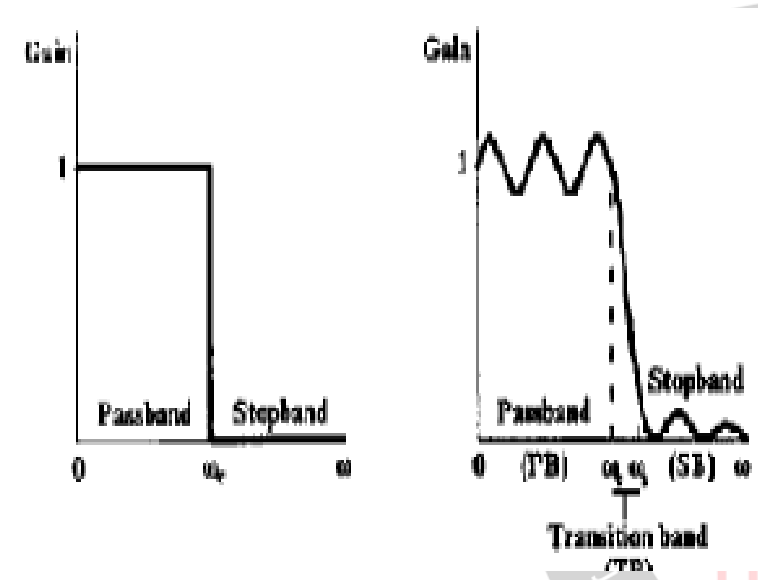

Fig. 2 Ideal Frequency Response of Active Low Pass Filter

The transfer function of a second-order low-pass filter can be express in s- domain

$\mathrm{H}(\mathrm{S})=\mathrm{H}_{\mathrm{o}} \mathrm{W}_{\mathrm{n}}^{2} /\left(\mathrm{S}^{2}+2 \varepsilon \mathrm{W}_{\mathrm{n}} \mathrm{S}+\mathrm{W}_{\mathrm{n}}^{2}\right)$

And frequency component

$$
\mathrm{W}_{\mathrm{n}}=\left(1 / \mathrm{R}_{1} \mathrm{C}_{1} \mathrm{R}_{2} \mathrm{C}_{2}\right)^{1 / 2}
$$

From the last one decade, many researchers have designed active low pass RC filter using n-order which propose for different applications using different topology. Preeti R. Lawhale had proposed and designed low pass filter for cut off frequency $1.67 \mathrm{~Hz}$ using forth order for the biomedical applications. This designed active filter is useful for low power consumption and low biomedical frequency [8][9]. While, M. Renuka innovate the forth order active low pass filter using millar compensation techniques with $600 \mathrm{nW}$ low power consumption. This innovative filter is suitable for $10 \mathrm{mHz}-100 \mathrm{~Hz}$ biomedical frequency range [10]. Similarly, in 2018, Low pass filter is designed for $250 \mathrm{~Hz}$ in case of ECG and $200 \mathrm{~Hz}$ in case of EEG with maximum 9.4nW low power consumption [11].

\section{PROPOSED CIRCUIT DESIGN USING COMPLEMENTARY COMPOUND PAIR}

The innovative circuit diagram of Complementary compound low pass filter is designed using the new transistor like RKTG pair. In this paper, we proposed the second order low pass RC filter using active component such as CMOS amplifier based on complementary compound pair (RKTG Pair) with very low value of resistor and capacitor. This proposed filter includes two complementary compound CMOS pair. These are connected in parallel with the simple current mirror to produce high current gain. The output of second complementary compound pair is feedback in the input of first complementary compound pair with two resistors and capacitors. The circuit diagram of proposed second order CMOS active low pass RC filter is shown in "Fig.3". This type of CMOS amplifier used in any type of filter is suitable to provide voltage amplification, signal isolation, buffering etc. In Fig.3, the value of resistor and capacitor is playing the vital role to increase and decrease the cut off frequency at $3 \mathrm{~dB}$. We can decrease the value of capacitor $\mathrm{nH}$ to $\mathrm{pH}$ with increasing the range of pass band $\mathrm{Hz}$ to MHz. It is shown in "tabular table 1".

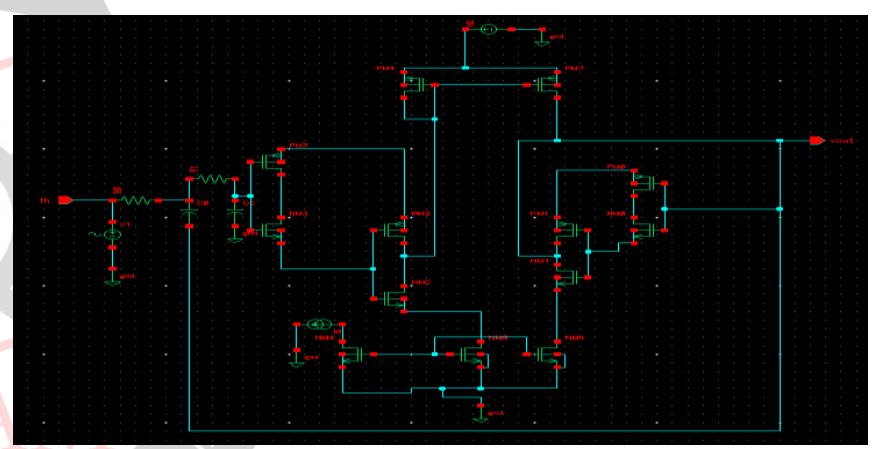

Fig.3 Proposed Second Order CMOS Active Low Pass RC Filter Tabular Table-1

Output voltage $=4.861 \mathrm{~V}$ if $\mathrm{V}_{\text {in }}=1 \mathrm{mV}$

\begin{tabular}{|l|l|l|l|}
\hline S.No. & $\mathrm{R} 1$ or R2 & $\mathrm{C} 1$ or $\mathrm{C} 2$ & $\begin{array}{l}\text { Cut } \\
\text { frequency }\end{array}$ \\
\hline 1 & $1 \mathrm{~K} \Omega$ & $100 \mathrm{nF}$ & $103 \mathrm{~Hz}$ \\
\hline 2 & $1 \mathrm{~K} \Omega$ & $10 \mathrm{nF}$ & $1.05 \mathrm{KHz}$ \\
\hline 3 & $1 \mathrm{~K} \Omega$ & $1 \mathrm{nF}$ & $10.52 \mathrm{KHz}$ \\
\hline 4 & $1 \mathrm{~K} \Omega$ & $100 \mathrm{pF}$ & $103 \mathrm{KHz}$ \\
\hline 5 & $1 \mathrm{~K} \Omega$ & $10 \mathrm{pF}$ & $1.01 \mathrm{MHz}$ \\
\hline
\end{tabular}

According the table-1, Cut off frequency is increasing with respect to the capacitor decreases by by one decade times respectively. Hence The proposed second order active low pass filter can be used as a band pass active filter for low frequency applications like- Biomedical signal processing, Digital signal processing etc. by decreasing the value of capacitor up to $\mu \mathrm{F}$. This filter behaves as a highest band of low frequency up to $\mu \mathrm{Hz}$ to $\mathrm{Hz}$ at the low value of capacitor. At this time, second order low pass filter behave as a band pass filter to pass the band of low frequency. Hence, it can be valuable to design biomedical portable devices for biomedical applications. This type of active 
low pass filter can be designed as a high pass filter and band stop filter with the help of changing the value of passive components used in filter. This proposed second order low pass filter is simulated on $180 \mathrm{~nm}$ cadence virtuoso tool.

\section{RESULT DISCUSSION WITH SIMULATION}

In this paper we design a second order low pass filter using complementary compound pair. As we applied the $1 \mathrm{mV}$ $50 \mathrm{~Hz}$ input power supply on the input of first complementary compound pair through the resistor and capacitor, then the output obtained $4.86 \mathrm{~V}$ with more amplification. This measured value represents the high gain shown in "Fig.4" by the transient analysis of proposed low pass RC filter. Generally, the second order low pass $\mathrm{RC}$ filter has the cut off frequency at $40 \mathrm{db} /$ decade to give the better frequency response. The frequency response of proposed filter is shown in "Fig.5" by the AC analysis. This proposed filter provides the minimum cut off frequency $\mathrm{f}_{1}=57.03 \mu \mathrm{Hz}$ and highest cut off frequency $\mathrm{f}_{2}=1.01 \mathrm{MHz}$ at $3 \mathrm{~dB}$ by changing the value of passive elements. It is very low frequency passed by this filter. This proposed filter exhibits the highest frequency range.

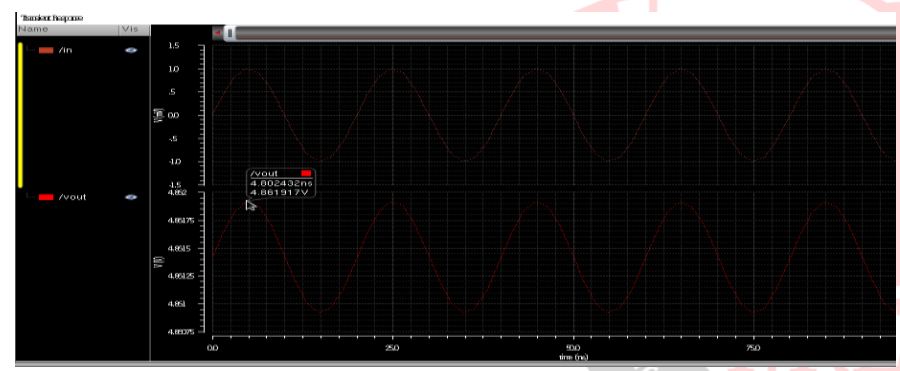

Fig.4 Transient Analysis of Second Order Active Low Pass RC Filter

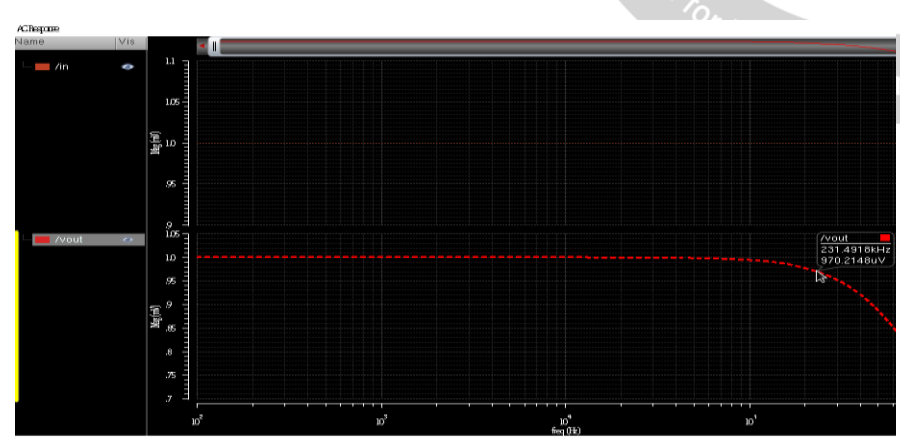

Fig.5 Frequency Response of Second Order Low Pass RC Filter (Proposed)

"Fig.5" shows that the low frequency up to $100 \mathrm{~Hz}$ to $\mathrm{MHz}$ is pass through this proposed second order low pass filter. So it can be used as a high pass filter and low frequency high range band pass filter also by changing the value of resistor and capacitor.

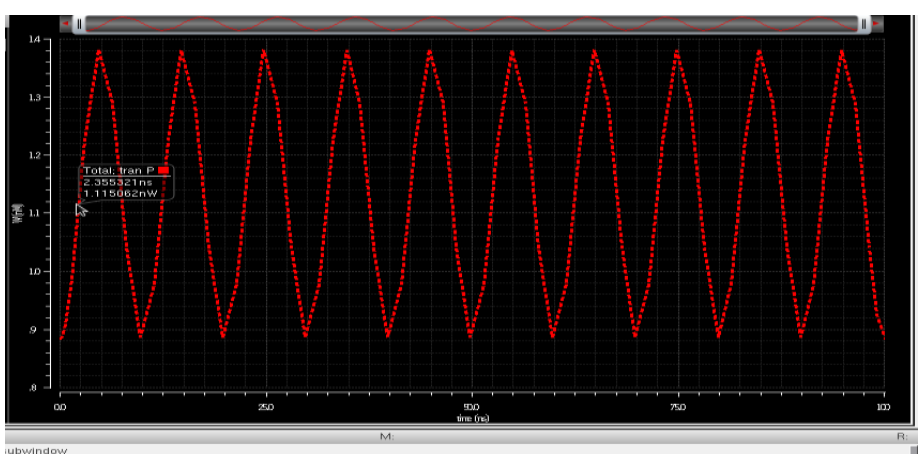

Fig.6 Power analysis of second order active low pass filter

The power analysis of proposed second order active low pass filter using complementary compound pair is shown in above "Fig.6" with $1.21 \mathrm{nW}$. It is very low power consumption then the others. "Fig.7" also shows the gain margin and phase margin calculation by the simulation of proposed second order low pass filter on $180 \mathrm{~nm}$ cadence virtuoso tool.

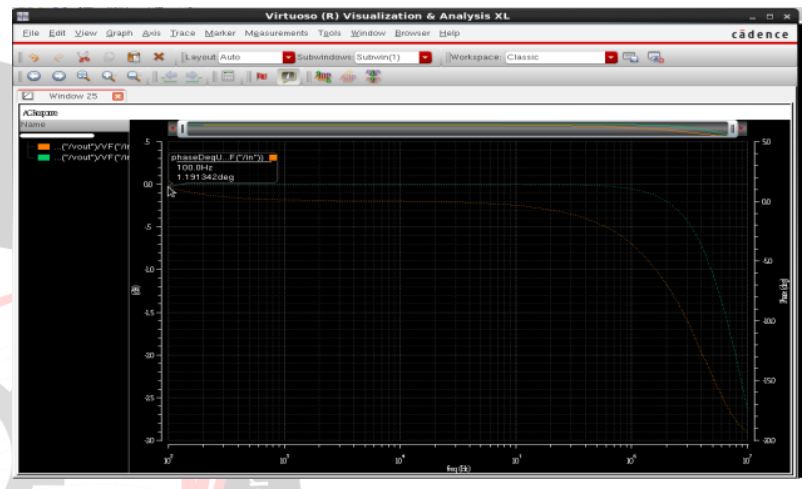

Fig.7 Gain and Phase Margin of second order active low pass filter

\section{CONCLUSION}

Active low pass RC filters have been designed using different number of order for low power and various high frequency range of low frequency. These have many issues like various filters for various frequency range based on active and passive components. Passive components are not suitable for the low cut off frequency low pass filter. Hence this paper proposed the designing of active low pass filter using complementary compound pair. On the basis of result discussion, we found that the Complementary compound pair used CMOS amplifier for filter designing is very suitable to exceed the band of the frequency and decrease power consumption by the circuit. It provides large current gain than the other pair like- Darlington Pair and Szilkai Pair. This proposed low pass RC active filter provide varying cut off frequency range $100 \mathrm{~Hz}-1 \mathrm{MHz}$ for different applications like- Biomedical applications, broadband applications etc. by decreasing the value of capacitor $100 \mathrm{nH}-10 \mathrm{pH}$ at $1 \mathrm{mV}$ input supply with $1.21 \mathrm{nW}$ low power consumption.

\section{FUTURE SCOPE}

In future, we can be design all types of active filters using Complementary compound pair with required $\mathrm{W} / \mathrm{L}$ ratio for advanced biomedical applications. 


\section{ACKNOWLEDGMENT}

This work is supported by the grant from the Major Research Project of University Grant Commission (UGC) New Delhi (Project ID.MRP-MAJOR-ELEC-201331956). Authors are thankful to University Grant Commission to provide financial support.

\section{REFERENCES}

[1] W. M. C. Sansen and P. M. Van Peteghem, “An area-efficient approach to the design of very-large time constants in switched-capacitor integrators," IEEE, Solid-State Circuits, Vol. SSC-19, No. 5, pp. 772780 , Oct. 1984

[2] Haidong Liu, Xiaohong Peng and Wuchen Wu, "Design of a Gm-C Low Pass Filter with Low Cutoff frequency," IEEE Microelectronics \& Electronics , pp. 125-128, January 2009

[3] Andras Timar and Marta Rencz, "Design issues of a low frequency low pass filter for medical applications using CMOS technology".

[4] Preeti R. Lawhale and Prof. Somulu G, " CMOS Based Low Pass Filter for Biomedical Applications," International Journal of Engineering Research and Applications (IJERA), ISSN: 2248-9622, April 2014

[5] Raj Kumar Tiwari and Gaya Prasad, "A New Circuit Model Of Low Voltage High Gain CMOS Compound Pair Amplifier" Published in International Journal of Electronics and Communication Engineering \& Technology (IJECET), ISSN 0976 -6464(Print), ISSN 0976 6472(Online), Volume 5, Issue 4, April (2014), pp. 65-71 (C IAEME, Journal Impact Factor (2014): 7.2836 (Calculated by GISI)

[6] Raj Kumar Tiwari, Gaya Prasad, "CMOS Compound Pair Wide Band Bio-Amplifier" Published in International Journal of Computational Engineering Research (IJCER), Vol.04, Issue 6, June2014, pp. 57-62 ISSN (e): 2250-3005. Impact Factor: 1.145, (Computed by African Quality Centre for Journals).

[7] Gaya Prasad, Raj Kumar Tiwari, Shiksha Jain and Ganga Ram Mishra, "Simulation Study of CMOS Compound Pair Amplifier," International Journal of Advance Research in Science and Engineering, Volume No. 07, Special Issue No. 01, April 2018, Impact Factor (2018): 2.83. ISSN No.(o) 2319-8354, (P) 2319-8346.

[8] Preeti R. Lawhale, Prof.Somulu G, "CMOS Based Low Pass Filter for Biomedical Applications", Research Article, International Journal of Engineering Research and Applications (IJERA,) ISSN: 22489622,2014

[9] Preeti R. Lawhale, Mayuri M.Soni, "Design of CMOS Based Low Pass Filter", Satellite Conference ICSTSD 2016 International Conference on Science and Technology for Sustainable Development, Kuala Lumpur, MALAYSIA, May 24-26, 2016

[10] M.Renuka, B.Divya and B.Preethi, "Active Low Pass Filter for Biomedical Applications," International Journal of Engineering Sciences \& Research Technology, ISSN: 2277-9655, December, 2017, DOI: 10.5281/zenodo.1116616.

[11] Puneet Kaushik, Mohit Jain, "Design of Low Power CMOS Low Pass Filter For Biomedical Application," International Journal Of Electrical Engineering \& Technology (IJEET), Volume 9, Issue 5, SeptOct 2018

[12] Raj Kumar Tiwari, Shiksha Jain, Gaya Prasad, "Complementary Compound Push Pull Power amplifier for Wide Frequency Band Aapplications Using CMOS nanotechnology," International Conference On Electrical and Electronics Engineering (ICE3-2020), 978-1-7281-4/20/\$31.00@2020IEEE.
[13] Shiksha Jain, "A Review: Performance Analysis of Voltage Controlled Differential Ring Oscillators Based On Delay Cell Using CMOS Nanotechnology," International Journal of Research and Analytical Reviews (IJRAR-2020), Vol 7, Issue 1, February 2020, http://doi.one/10.1729/Journal.23159.

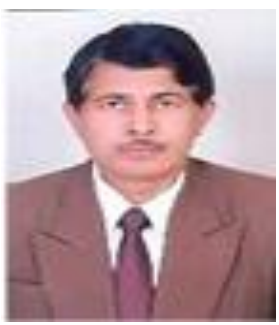

\section{Biography}

Raj Kumar Tiwari was born in Faizabad (UP), India in 1960. He received B.Sc and M.Sc degree with Gold Medal from Allahabad University. He qualified JRF(CSIR) and also obtained SRF (CSIR). He obtained P.hd degree from Dr. RML Awadh University in Physics. Presently he is serving as a professor and Ex. HOD in Department Of Physics and Electronics of Dr. R.L.A university Ayodhya. He has published more than 85 Research Papers in Journal and International/National Conferences. 13 students has completed Ph.D under his supervision. Presently he is working as a Dean Faculty of Science, Dr. Rammanohar Lohia Avadh University Ayodhya.

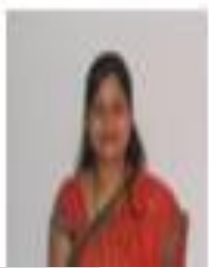

Shiksha Jain was born in Aligarh (UP), India in 1984. She received the B.Tech degree in Electronics \& Communication Engineering from ACET, under UP Technical University, India in 2005, M.Tech. degree in Digital Electronics from Gautam Budh Technical University, India in 2011, pursuing Phd in Electronics from Dr. Rammanohar Lohia Avadh University, India from 2016. Currently she is an assistant professor in Electronics \& Communication Engineering Department at Institute of Engineering and Technology under Dr. Rammanohar Lohia Avadh University, India. His research interest includes microprocessor, VLSI Design, Digital system and Electronics Circuit 